\title{
A prática pedagógica docente humanizadora vivenciada na educação de jovens e adultos: exercício intencional e formativo que requer ação-reflexão transformadora
}

\author{
Leitao, Edineide Souza Sá ${ }^{1}$ \\ Guedes, Marília Gabriela de Menezes²
}

\section{Resumo}

O artigo analisa a prática docente, na perspectiva humanizadora, como exercício dialógico e intencional que se articula à prática pedagógica institucional, contribuindo com a formação dos sujeitos nos processos de escolarização. As reflexões aqui apresentadas resultam de uma pesquisa realizada em um município da região metropolitana do Recife. A abordagem qualitativa presidiu a investigação tendo a coleta de dados utilizado a observação e a entrevista semiestruturada. A organização e tratamento dos dados fizeram-se através da Análise de Conteúdo de Bardin (2008). Os resultados mostraram aproximações da prática pedagógica docente analisada com os pressupostos da educação humanizadora freireana, na qual o diálogo, numa perspectiva crítica e amorosa, se apresentou como eixo articulador da relação docente-discente e do processo de produção do conhecimento.

Prática pedagógica docente. Educação Humanizadora. Diálogo. Paulo Freire. João Francisco de Souza.

\section{Abstracto}

El artículo analiza la práctica docente en la perspectiva humanizadora, como ejercicio dialógico e intencional que articula la práctica pedagógica institucional, contribuyendo con la formación de los sujetos en los procesos de escolarización. Las reflexiones presentadas aquí son el resultado de una encuesta realizada en una ciudad de la región metropolitana de Recife. El enfoque cualitativo presidió la investigación, en la recopilación de datos se ha utilizado la observación y la entrevista semi-estructurada. La organización y el tratamiento de los datos se ha realizado a través del Análisis de Contenido de Bardin (2008). Los resultados demuestraron acercamientos de la práctica pedagógica docente analisada a través de los pressupuestos de la educación humanizadora freireana, en la cual el diálogo, representado por una perspectiva crítica y amorosa, se presenta como eje articulador de la relacción docente-discente y de los processos de produción del conocimiento.

Práctica pedagógica docente. Educación humanizadora. Diálogo. Paulo Freire. João Francisco de Souza.

\footnotetext{
${ }^{1}$ Mestre em Educação pela UFPE, docente do SESI, Pernambuco. Membro da Cátedra Paulo Freire da UFPE.

2 Doutora em Educação pela UFPE, Professora Adjunta do Departamento de Métodos e Técnicas de Ensino da UFPE. Membro da Cátedra Paulo Freire da UFPE
} 


\section{Introdução}

O artigo trata da concepção de prática pedagógica docente, com foco no diálogo, na amorosidade e na criticidade. A partir de Paulo Freire (2009), tais conceitos trazem elementos que contribuem para a construção de aprendizagens que têm como horizonte a humanização dos sujeitos. Essas concepções se materializam em atitudes, escolhas e relações empreendidas na prática educativa em que os(as) estudantes são compreendidos como seres sociais, históricos e inconclusos, que ao desenvolverem, por meio do diálogo, a percepção crítica sobre a realidade, vão se tornando capazes de produzir seus próprios saberes e de criar condições para uma atuação mais efetiva na sociedade.

Nessa direção, a prática dialógica se constrói na relação horizontal entre sujeitos. Relação que nasce de uma visão crítica e gera múltiplos olhares críticos sobre a realidade. Nutre-se da amorosidade, compreendida como dimensão afetiva, política, epistemológica e ética. A prática dialógica emerge, portanto, do exercício reflexivo da fala e escuta entre professores(as) e estudantes, que buscam problematizar a realidade e encontrar alternativas de transformação; orienta-se pelo conhecimento como instrumento de desvelamento da realidade; considera o contexto histórico em que o saber foi construído; assenta-se na busca da autonomia dos(as) estudantes e no compromisso ético e político com a justiça social.

A perspectiva dialógica de educação é adotada por João Francisco de Souza (2007), quando entende a prática pedagógica como processo de formação humana institucional, coletiva e relacional. A prática pedagógica docente, por sua vez, é um dos núcleos constitutivos do processo de ensino e aprendizagem. Tal ideia, no entanto, não restringe a importância dessa prática nem o seu significado, ao contrário, a aproxima do entendimento de que a ação docente é relacional, formativa, intencional e sistematizada.

No escopo da pesquisa, adotamos o conceito de prática pedagógica docente formulado por Guimarães e Santiago (2013, p. 17), com base em Souza, as quais destacam: "[...] a prática pedagógica docente e/ou educativa é 
humana por isso social e relacional, com intencionalidade formativa, tendo a instituição como influenciadora e espaço de sua efetivação".

A perspectiva aqui retida é de uma intencionalidade formativa que, de um lado, opõe-se a formas de ensino voltadas apenas para a decodificação mecânica da linguagem escrita e, por outro lado, orienta-se por um projeto educativo provocador da reflexão e teorização crítica da existência humana, permitindo que cada estudante possa perceber e identificar as tramas sociais onde estão enredados seus conhecimentos e seus valores, seu modo de ser e estar no mundo.

É com essa compreensão que apresentamos, neste artigo, uma análise dos resultados de uma pesquisa ${ }^{3}$ que toma a prática de duas professoras da Educação de Jovens e Adultos (EJA), como objeto investigativo.

\section{Metodologia}

O caminho metodológico escolhido para esta investigação nos fez optar pela abordagem qualitativa, considerando sua pertinência e adequação. Como procedimentos e instrumentos de coleta de dados, recorremos à entrevista semiestruturada e à observação. A análise temática, uma das modalidades da Análise de Conteúdo, foi fundamental para a organização e o tratamento das informações coletadas e produzidas no campo.

A Secretaria de Educação de Olinda foi nossa opção de campo mais amplo dessa pesquisa. Inicialmente, a escolha foi estimulada pelos estudos de Guedes (2012), que buscou compreender a contribuição de Paulo Freire na formulação de políticas e práticas curriculares nos sistemas de ensino do estado de Pernambuco.

A citada autora apontou, além da Secretaria de Educação do Estado de Pernambuco, cinco municípios da região metropolitana de Recife (RMR) Cabo de Santo Agostinho, Jaboatão dos Guararapes, Camaragibe, Olinda e Recife - os quais revelaram, em suas propostas curriculares, indícios do pensamento político-pedagógico de Paulo Freire. A definição pelo município de

\footnotetext{
${ }^{3}$ Dissertação intitulada: "A prática pedagógica docente na perspectiva da humanização em Paulo Freire". Recife: Universidade Federal de Pernambuco. Programa de Pós-graduação em Educação, sob a orientação da Profa. Dra ${ }^{a}$. Maria Eliete Santiago.
} 
Olinda ocorreu, posteriormente, após entrevistas realizadas com a Assessora do Gabinete da Secretaria e com a Coordenadora da Divisão de Educação de Jovens e Adultos, as quais destacaram o trabalho que vem sendo desenvolvido pela Coordenação de Educação de Jovens e Adultos, no sentido de reduzir o quantitativo de evasão, bem como, realizar iniciativas, em solidariedade com gestores(as) e professores(as), de estimular ações de incentivo e valorização de jovens e adultos(as) que estudam em classes da EJA.

Através dessas entrevistas, vimos que o pensamento político-pedagógico de Paulo Freire constituiu-se uma referência histórica no município de Olinda desde 1996, período em que foi criado o Centro de Educação de Jovens e Adultos (CEJA), sob a gestão do então prefeito de Olinda, Germano Coelho, e do professor João Francisco de Souza, titular à época, da Secretaria de Educação. Essa constatação corrobora com o que sustenta Minayo (2002) sobre a entrevista, que a entende como um instrumento fundamental para que o(a) pesquisador(a) possa obter informações contidas na fala dos atores(as) sociais, sendo possível aprofundar conhecimentos, além de esclarecer dados sobre o objeto de pesquisa.

O CEJA representou uma proposta inovadora e as ações que foram desenvolvidas nesse espaço tiveram repercussões, tanto em nível regional como nacional. As concepções pedagógicas que fundamentaram o projeto desenvolvido pelo CEJA têm referência no pensamento freireano, à medida que se orientava por uma proposta educativa crítica, em que a formação de professores se realizava de forma contínua.

Objetivava-se a consolidação da EJA como modalidade de ensino com características próprias, procurando estabelecer articulações com as necessidades de vida, trabalho e participação política e social das pessoas.

Diante disso, nossa opção pela EJA em Olinda fundamenta-se por compreendermos que as ações que vêm sendo empreendidas no município sustentavam-se em princípios humanizadores freireanos, os quais orientaram a proposta educativa do CEJA e que permanecem inspirando as ações da Coordenação de Adultos até os dias atuais, refletindo-se no trabalho pedagógico dos (as) professores(as). 
Para conhecer a materialização dos princípios da educação na perspectiva da humanização de Paulo Freire, na prática pedagógica docente que se realiza no chão da escola, nos valemos da observação. Tura (2011, p. 189) considera a observação um procedimento que possibilita ao pesquisador/a adentrar à vida de um grupo, "[...] com o intuito de desvendar as redes de significados produzidos e comunicados nas relações interpessoais. Há segredos do grupo, fórmulas, padrões de conduta, silêncios e códigos que podem ser desvelados".

Desta forma, buscamos na observação da prática pedagógica de duas professoras da EJA, considerar gestos, atitudes e ações que acontecem na prática educativa, sem perder de vista as peculiaridades dos sujeitos e do espaço em que estão incluídos. Atentamos, também, para o modo como os materiais didáticos, os conteúdos e as atividades realizadas eram escolhidos e abordados nas aulas, articulando-os com os pressupostos do diálogo, amorosidade e criticidade tratados na teoria pedagógica freireana.

Organizamos os dados a partir das situações de ensino apresentadas nas práticas das professoras, ou seja, a partir das diferentes atividades desenvolvidas com os(as) estudantes, de forma sistemática. As discussões e os resultados dessa análise serão discutidos a seguir.

\section{Resultados e discussões}

Para compreender a organização do cotidiano da sala de aula e os cenários em que foram produzidos os saberes, partimos da compreensão freireana de que a ação docente não se faz sem a discente. Assim, entendemos que as concepções, as metodologias, as articulações estabelecidas entre o discurso e a prática revelam as bases teórico-práticas que orientam o trabalho do(a) professor(a) na relação com os(as) estudantes e no trato do conhecimento.

Desta forma, as professoras procuraram construir situações de ensino alegres e desafiadoras, que buscassem superar a visão compartimentada nos processos de produção de conhecimento. Privilegiaram propostas dialógicas que favorecessem a interação da turma e a articulação entre as temáticas, 
considerando o universo cultural dos(as) estudantes; buscaram construir relações democráticas, não impondo os conhecimentos, mas criando espaço e fazendo pequenas intervenções para que todos(as) pudessem exercer o direito à fala e à escuta. Com isso, descrevemos e analisamos a seguir três situações de produção de conhecimento desenvolvidas nas práticas das professoras.

\subsection{Leitura, produção e interpretação de diferentes tipos de gêneros textuais: um texto de propaganda e um poema}

O incentivo à leitura e interpretação de diferentes gêneros textuais foi uma das situações de ensino nas quais as professoras procuraram promover a discussão do conteúdo com a participação dos(as) estudantes de forma efetiva. Nesse sentido, um texto de propaganda e um poema foram utilizados como recurso didático.

Em relação à propaganda, foi feito uso de um texto escrito no tempo do Brasil Imperial, publicado pelo Almanak Laemmert, no ano de 1885, que apresenta uma propaganda de uma fábrica de cerveja, instalada no Rio de Janeiro, naquele ano (Figura 1). O objetivo desta atividade foi contribuir para que os(as) estudantes exercitassem a análise e a compreensão textual, por meio das características do gênero propaganda, dando, ainda, continuidade ao estudo da história do Brasil.

Figura 1 - Gênero textual propaganda

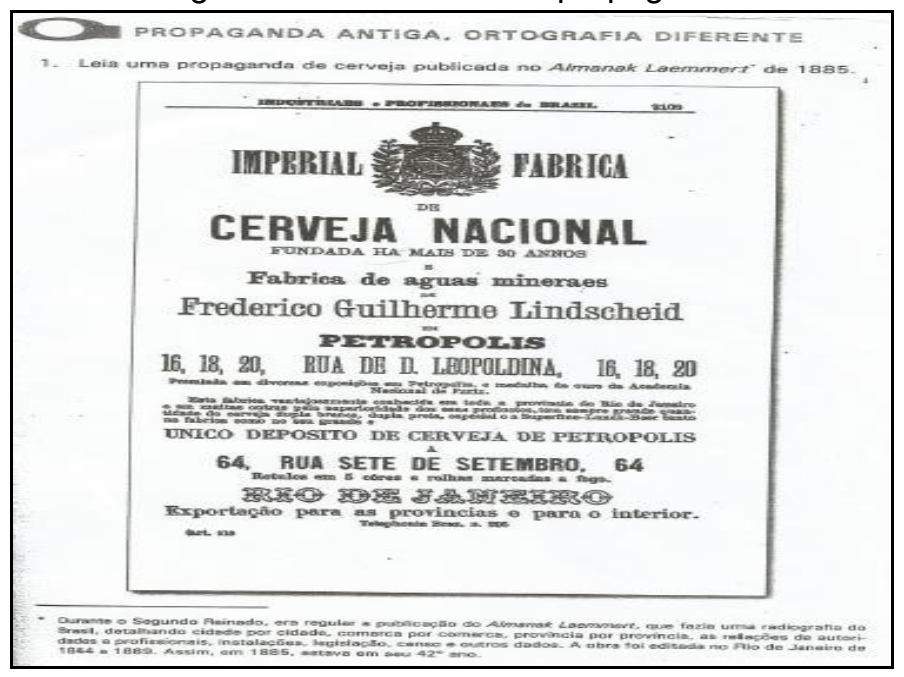

Fonte: Almanak Laemmert, 1885. 
Nessa situação de ensino, a professora procurou iniciar o assunto, contextualizando o texto e mostrando a relação do seu conteúdo com as discussões sobre gênero textual que havia trabalhado em Língua Portuguesa e os assuntos de História, conforme o extrato do diário de campo:

Professora: "Observem que nessa propaganda vemos que fala de uma fábrica de cerveja que existia há 131 anos. Agora vocês imaginem como eram as fábricas naquela época. Será que tinham a organização que vemos hoje?". Um estudante diz: "Eu acho que não, professora, porque as coisas hoje mudaram, avançaram. Quando eu trabalhava na fábrica, as coisas não eram como é hoje. Eu mesmo entrava e saia das câmaras frias de sorvete e nem recebia adicional pela insalubridade".

Outra estudante lembra: "Eu trabalhava numa fábrica e ficava com a mão cheia de calo e nem recebia luva, nem óculos de proteção, nem nada. Hoje é melhor.".

A professora diz: "E o senhor seu A, o que acha? E você $L$ ?"

Seu A responde: "Eu nem sei professora, mas eu acho que os sindicatos eram melhores antes do que agora".

A professora diz: "Sim, eu também concordo, a maioria deles hoje tem envolvimento com os empresários".

Seu A destaca: "No meu tempo não tinha isso da gente não saber o que acontecia. O sindicato falava, se reunia".

A professora ressalta: "Pois é, temos uma sociedade que é contraditória. Nós avançamos em direitos e, por outro lado, o jogo de interesses políticos e econômicos faz as coisas, às vezes, recuarem, por isso a gente precisa se esclarecer para perceber o que está por traz das atitudes das lideranças políticas".

Caderno de campo, 2015.

Na condução do momento de produção de conhecimento, as professoras apostavam na capacidade de discernimento dos sujeitos aprendentes, no seu potencial para perceber a evolução do tempo, situando-se nele de forma crítica e interferindo em seu direcionamento. 
Revelaram, ainda, que o contexto social e político pode dificultar os sujeitos de pensar de forma liberta sobre a realidade, mas também, pode ir sendo superado, no ato mesmo de pensar criticamente sobre os desafios impostos, ao passo que se organiza a ação, por meio do estudo, da decisão, da criação. Desse modo, estimulam a formação de pessoas que possam se relacionar de maneira mais recíproca e solidária.

O trabalho realizado a partir da poesia intitulada "O Açúcar", retirada do livro didático de EJA (Figura 2), serviu para evidenciar uma prática pedagógica na qual estudantes e professoras atuam como sujeitos no processo de produção do conhecimento e o texto é tomado como objeto de reflexão sobre as condições do trabalhador rural que produz o açúcar.

Figura 2 - Poesia: O Açúcar

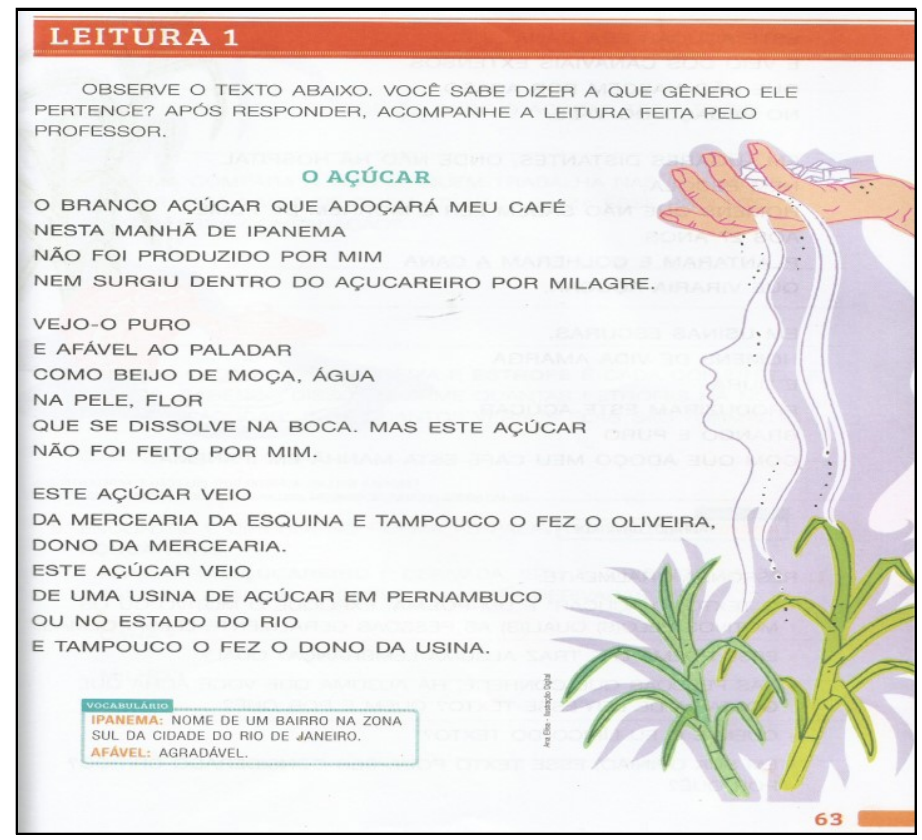

Fonte: Linguagem. É bom aprender, vol. 1, 2013.

Após a professora estimular o interesse da turma pelo poema, duas estudantes solicitaram realizar a leitura. Todos(as) concordaram e as ouviram com atenção. Diferentes compreensões sobre a poesia foram apresentadas, dentre as quais: a falta de conhecimento que as pessoas têm, de um modo geral, sobre a vida sacrificada dos(as) trabalhadores(as) do campo, principalmente os(as) cortadores(as) de cana; sobre os baixos salários e, em 
muitos casos, a precariedade das condições de trabalho. Foram discutidos, também, os aspectos que compõem o gênero poesia, como estrofes, versos e linguagem subjetiva. Nessa direção, os(as) estudantes conseguiam apontar no texto os trechos que expressavam emoção e sofrimento.

As atividades indicavam o esforço para a formação de leitores(as) críticos(as) que conseguiam ampliar o sentido do texto, explorando os temas nele apresentados e fazendo correlações entre o conteúdo e o objeto sobre o qual estavam estudando. É importante ressaltar o empenho da professora no incentivo para que estudantes pudessem expor seus saberes e experiências, contando sobre o trabalho daqueles que, um dia, foram cortadores(as) de cana. Vários aspectos foram ressaltados: o sofrimento causado pelo trabalho, a falta de registro na carteira, a sobrecarga de trabalho e, ainda, o fato de terem trabalhado desde criança.

Assim, as condições criadas pela professora oportunizavam discutir os temas que surgiam, revelando uma postura crítica e humilde da professora, ao considerar a leitura de mundo dos (as) estudantes como conhecimentos válidos e importantes na experiência educativa, ao mesmo tempo em que reconhece a importância de avançar essa percepção, como podemos ver no extrato a seguir:

Professora: "Observem quanta coisa já mudou. Hoje, há uma exigência maior para a carteira assinada. Temos como reivindicar através da Justiça do Trabalho. Do mesmo jeito, o trabalho infantil é proibido. Temos leis para proteger o menor."

Caderno de campo, 2015.

Assim, o processo de alfabetização orientado pelas professoras, ao se opor a métodos de ensino abstratos e distantes da realidade dos (as) estudantes, aproxima-se da visão de Paulo Freire (2006), tendo em vista que palavras e frases do texto foram associadas à realidade concreta da vida dos (as) estudantes e partiram da tematização. Nessa direção, a prática dessas professoras considerariam os (as) estudantes sujeitos coprodutores do conhecimento, ao garantir o direito de pronúncia de sua palavra e ao buscar formas de contribuir para o empoderamento desses sujeitos. A ação educativa 
favoreceu também interação e a cumplicidade entre os (as) estudantes. Nesse momento, havia um clima de respeito, em que a turma se escutava e descrevia um para o outro sobre suas vivências, conforme pode ser visto no trecho a seguir:

Professora: "Com qual idade vocês começaram a trabalhar no corte de cana"? Um estudante respondeu: "Com mais ou menos 11 anos".

O outro afirmou: "Comigo foi desde os 10 anos e o pior é que eu fiquei sem receber meus direitos, professora".

Outras duas estudantes se aproximam e trocam com os colegas relatos de experiências como cortadoras de cana.

Caderno de campo, 2015.

Nesta situação de ensino, teria ocorrido a valorização da escuta dos depoimentos dos(as) estudantes pelas docentes, a organização das oportunidades das falas de quem quisesse dar o seu depoimento. Esse exercício de fala e escuta colaborava para desenvolver a disciplina intelectual de esperar a vez de falar; de escutar enquanto o outro falava; respeitar as diferentes opiniões; ter postura atenta no ato comunicativo.

\subsection{Atividades de produção de texto como instrumento de conscientização crítica}

O desenvolvimento da produção escrita de textos consistiu numa abordagem dialógico-crítica e na inter-relação entre os conteúdos, situações de ensino, em que a produção textual foi o resultado de reflexões teórico-práticas, que partiram da leitura de textos e da análise do âmbito social e político das quais os(as) estudantes participam.

As professoras buscaram, através do estimulo à produção escrita, problematizar a temática da acessibilidade, estimular a percepção crítica dos (as) estudantes sobre as condições precárias das ruas, das calçadas e da violência no trânsito e contribuir para que ampliassem o conhecimento sobre o assunto, firmando posicionamento, desenvolvendo a sensibilidade e a solidariedade diante do problema. Em Souza (2007, p. 102), a prática educativa que defende como utopia "[...] a construção dessa democracia enquanto forma 
de vida e sistema social contém como seus temas constitutivos o poder e o desenvolvimento integral do ser humano e da sociedade".

Tomamos conhecimento de que esta atividade foi sugerida pela Coordenação de Educação de Jovens e Adultos do Município, que propôs a cada turma da EJA levar para um próximo Encontro de Educação de Jovens e Adultos uma produção escrita que contemplasse a temática da inclusão social.

$\mathrm{Na}$ ocasião, foi solicitado pelas professoras que os (as) estudantes escrevessem sobre a acessibilidade, aproveitando as informações e debates sobre o conteúdo discutido na aula anterior. Uma das redações (Figura 3) produzidas neste dia, foi apresentada à turma, como exemplo de um bom texto produzido, sem contudo, desconsiderar os demais textos construídos pelo grupo.

Figura 3 - Texto Cadeirante

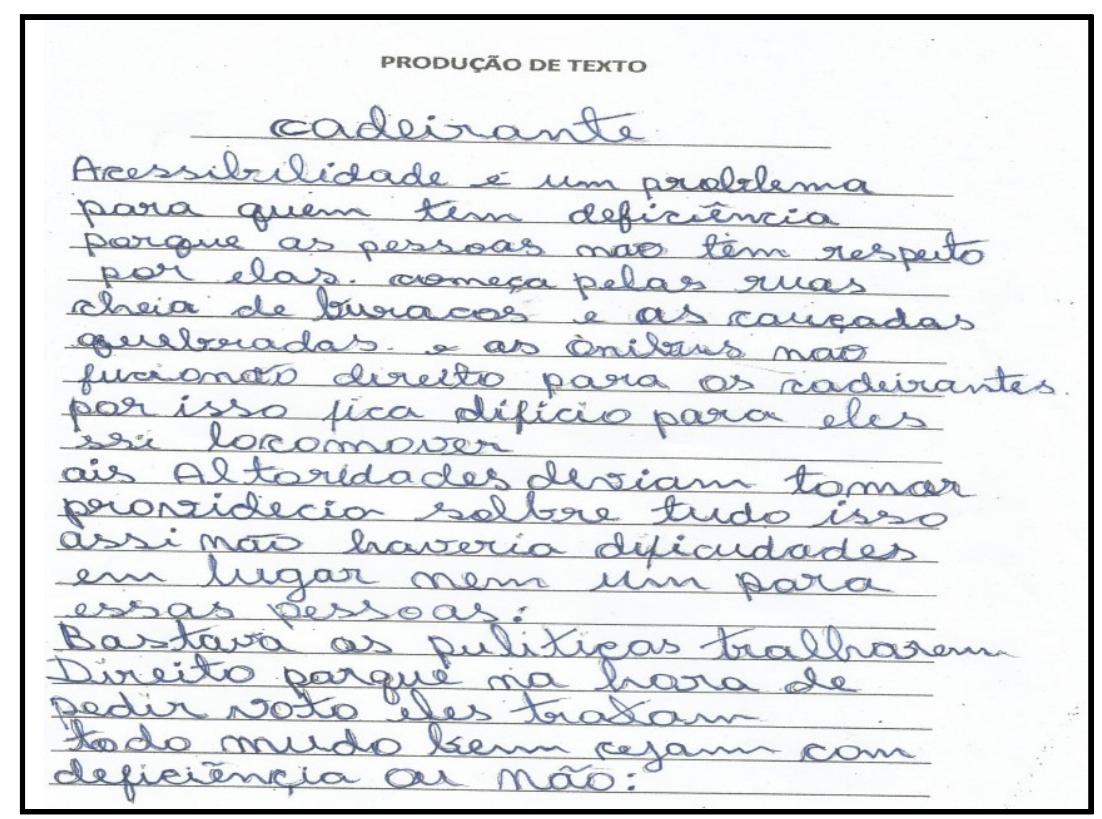

Fonte: Texto produzido por uma estudante de EJA, 2015.

Durante a leitura do texto pela autora, os (as) colegas escutavam atentamente e, após o término, a professora elogiou, procurando valorizar a capacidade de produção e autonomia da estudante. Na ocasião, foi solicitada a opinião da turma sobre a redação e o conteúdo do texto. O envolvimento dos (as) estudantes era evidenciado na participação e no pronunciamento da maioria sobre o texto lido, como podemos acompanhar a seguir: 
Professora: "O que acharam do texto da colega"?

Uma estudante respondeu: "Acho que o texto de M. quer dizer que precisa melhorar a capacidade dos políticos em melhorar a vida das pessoas, devia ter mais iluminação, cuidado com buracos."

A professora pediu atenção para que todos pudessem falar e diz que é importante ouvir a opinião de cada um (a).

Outro colega disse: "Acho que precisa melhorar as condições das ruas, das calçadas e dos ônibus."

Outra estudante frisou: "Precisa melhorar a iluminação."

Outro disse: "Para passar na rua em frente à escola, precisa ter muito cuidado, porque os carros e ônibus não param para ninguém passar, mesmo vendo que aqui é uma escola."

A professora sintetizou: "Pois é, pelo que vemos a questão da acessibilidade envolve problemas, como consciência dos motoristas, melhorias nas calçadas, iluminação, limpeza urbana. Quer dizer, depende das ações e da consciência de cada ser humano, nosso respeito pelo outro nas filas, no trânsito, quando estamos dirigindo um carro, uma moto. Mas, também, tem relação com as lideranças políticas”.

Caderno de campo, 2015.

A discussão da temática da acessibilidade, estimulou a percepção crítica dos(as) estudantes sobre as condições precárias das ruas, das calçadas e da violência no trânsito. Contribuiu para que ampliassem os conhecimentos sobre o assunto, tomassem posicionamento, desenvolvendo a sensibilidade e a solidariedade diante do problema.

\section{Considerações finais}

$\mathrm{Na}$ prática pedagógica docente-discente analisada, o diálogo ganhou centralidade, gerando duas subtemáticas: o diálogo na perspectiva da criticidade e da amorosidade. Todavia, as categorias evidenciadas, não foram compreendidas de forma fragmentada, mas inter-relacionadas.

A prática dialógica, na perspectiva da criticidade, se deu no reconhecimento do ser humano como ser histórico e social; na valorização pela 
leitura de mundo dos (as) estudantes e pela problematização da realidade com vistas à mudança social; na tematização dos conteúdos; no rigor presente nas atitudes das professoras, na seleção dos materiais, dos conteúdos e atividades. A prática educativa dialógica, na perspectiva da amorosidade, expressou-se no afeto e cuidado pelos(as) estudantes; no exercício da fala e escuta, no respeito aos saberes e na confiança na capacidade de produzirem conhecimento.

A ação das professoras representou também um esforço pela permanência dos (as) estudantes na escola, procurando torná-la um espaço prazeroso e de participação. Além disso, demonstravam interesse pelos temas e eventos culturais discutidos e promovidos pela Coordenação de Jovens e Adultos, envolvendo a turma para que participassem.

Nesse sentido, vimos que é possível acontecer no chão da escola, aproximações com a educação na perspectiva da humanização freireana, bem como, com a compreensão de Souza (2007) sobre a prática docente como instituinte da prática pedagógica institucional.

\section{Referências}

BARDIN, L. Análise de conteúdo. 5. ed. Lisboa/Portugal: Edições 70, 2008.

FREIRE, P. Pedagogia do oprimido. 31. ed. Rio de Janeiro: Paz e Terra, 2009..

Pedagogia da autonomia: saberes necessários à prática educativa. 28. ed. São Paulo: Paz e Terra, 2003.

Conscientização: teoria e prática da libertação: uma introdução ao pensamento de Paulo Freire. São Paulo: Centauro, 2006.

GUEDES, M. G. de M.. Contribuição de Paulo Freire para as políticas e práticas curriculares nos sistemas de ensino. 2012. Tese (Doutorado em Educação) Centro de Educação, Universidade Federal de Pernambuco, Recife, 2012.

SOUZA, J. F. E a educação popular: ¿¿ Quê ?? Uma Pedagogia para fundamentar a educação, inclusive escolar, necessária ao povo brasileiro. Recife: Bagaço, 2007.

TURA, M. L. R. A observação do cotidiano escolar. In: ZAGO, N.; CARVALHO, M. P.; VILELA, R. A. T. (Orgs.). Itinerários de Pesquisa. Rio de Janeiro: Lamparina, 2011, p. 183-206. 
GUIMARÃES, O; SANTIAGO, E. A compreensão sobre prática pedagógica nas pesquisas veiculadas nos encontros de pesquisa em educação do norte e nordeste. Anais do XXI Encontro de Pesquisa do Norte Nordeste. Universidade Federal de Pernambuco, Recife, 2013.

LÜDKE, M.; ANDRÉ, M. E. D. A. Pesquisa em educação: abordagens qualitativas. São Paulo: EPU, 1986.

MINAYO, M. C. de S.. Pesquisa social - Teoria, Método e Criatividade. Petrópolis, RJ: Vozes, 2002. 